\title{
Wykonanie metodą napawania powłoki ze stopu międzymetalicznego FeAl na stali konstrukcyjnej
}

\author{
The performance on the method of welding \\ in intermetallic alloy FeAl coating on the structural steel
}

\section{Streszczenie}

Wdrożenie nowych materiałów do praktyki przemysłowej pozwala na konstrukcję trwalszych i bardziej wytrzymałych części maszyn przeznaczonych do pracy w wysokiej temperaturze oraz ekstremalnych warunkach. W artykule analizowano zastosowanie metody napawania do wykonania napoiny ze stopu na osnowie fazy międzymetalicznej Fe40Al5CrTiB na powierzchni stali S235JR. Proces prowadzono metodą TIG w atmosferze gazu obojętnego przy zastosowaniu prądu stałego (DC-). Próbki napawano w trzech wariantach: jednościegowym, wielościegowym oraz wielowarstwowym. Po procesie napawania przeprowadzono badania za pomocą mikroskopu świetlnego (LM), elektronowego mikroskopu skaningowego oraz dokonano pomiarów twardości metodą Vickersa (HV). Technologia ta może być zastosowana w przyszłości, na przykład w przemyśle energetycznym do wytworzenia powierzchni żaroodpornych.

Słowa kluczowe: powłoki; FeAl; fazy międzymetaliczne; niezgodności; TIG

\begin{abstract}
Implementation of new materials into industrial practice allows to build more durable and reliable machine parts suitable to operate at high temperature and other special conditions. The paper analyzes implementation of welding method to make intermetallic surface Fe40Al5CrTiB on material grade S235JR. The process was made with tungsten inert gas (TIG) and with the use of reserved polarity direct current (DC-). Welded sample was made as: single bead, multi bead and as multilayer. After the welding process, samples were tested with light microscopy (LM), scanning electron microscopy (SEM) and Vickers hardness (HV). This technology can by used to develop resistance surfaced in the power industry in the future.
\end{abstract}

Keywords: coating; FeAl; intermetallic phase; imperfection; TIG

\section{Wstęp}

Obecnie w celu podwyższenia trwałości urządzeń poza doborem materiału i warunków pracy, stosuje się napawanie powierzchni roboczych specjalnymi elektrodami lub drutami. Napawanie jest jednym z nowoczesnych procesów regeneracji części maszyn i urządzeń. Uzyskanie warstwy materiału spełniającej kryteria wskazane dla konstrukcji pozwoli na zaspokojenie zapotrzebowania rynku, redukując tym samym problem związany z ich trwałością. Nowatorskim sposobem poprawy właściwości jest modyfikacja warstwy wierzchniej poprzez napawanie drutem ze stopu na osnowie fazy międzymetalicznej Fe40Al5Cr0,2TiB. Zmiana właściwości materiału zależy od wymiarów (grubości) napawanej warstwy. Stopy na osnowie fazy międzymetalicznej FeAl charakteryzują się bardzo dobrą odpornością korozyjną w wysokiej temperaturze, jak również odpornością na korozję zarówno w atmosferach utleniających, jak i zawierających związki siarki, a także na nawęglanie. Stopy na osnowie fazy międzymetalicznej FeAl mają wiele zalet, do których należy: niska gęstość w stosunku do stali, względnie niska cena surowców oraz wysoka odporność na ścieranie. Do wad tych materiałów zaliczyć należy kruchość w temperaturze zarówno otoczenia, jak i podwyższonej. Proces napawania materiałem wykonanym ze stopu na osnowie fazy międzymetalicznej FeAl powoduje znaczną poprawę właściwości mechanicznych. Na rysunku 1 przedstawiono mikrostrukturę stopu po krystalizacji i po napawaniu. Potencjalne zastosowanie stopów na osnowie fazy międzymetalicznej FeAl obejmują elementy kotłów i palników, druty nawojowe, filtry gazowe, elementy w turbinach gazowych, turbosprężarkach, przewody rurowe, wymienniki ciepła, grzejniki elektryczne. Przewiduje się, że mogą znaleźć one zastosowanie w energetyce, przemyśle chemicznym, przemyśle

Dr inż. Janusz Cebulski; mgr inż. Dorota Pasek - Politechnika Śląska; dr inż. Robert Bęczkowski - Politechnika Częstochowska.

Autor korespondencyjny/Corresponding author: rbeczkowski@spaw.pcz.pl 
petrochemicznym, przemyśle motoryzacyjnym, lotniczym, okrętowym i hutnictwie $[1 \div 11]$.

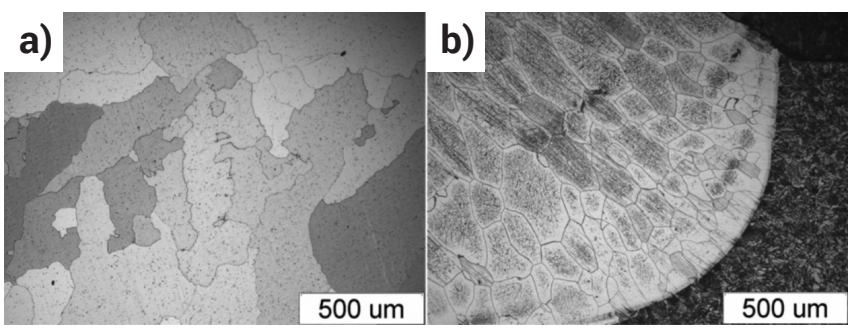

Rys. 1. Mikrostruktura stopu Fe40Al5Cr0,2TiB: a) materiał po krystalizacji, b) po napawaniu

Fig. 1. Microstructure of the Fe40Al5CrTiB alloy: a) material after crystallization, b) after welding

\section{Materiały i metodyka badawcza}

Materiał do badań stanowił stop na osnowie fazy międzymetalicznej FeAl, którego skład chemiczny przedstawiono w tablicy I. Do wytopu użyto czystych składników: technicznie czyste żelazo ARMCO oraz aluminium ARO o stopniu czystości 99,99\% mas. Przeprowadzono wyżarzanie homogenizujące $w$ temperaturze $1050^{\circ} \mathrm{C} w$ ciągu $72 \mathrm{~h}$ w celu ujednorodnienia składu chemicznego. Wytwarzanie stopów na osnowie faz międzymetalicznych FeAl związane jest z pewnymi trudnościami wynikającymi z właściwości materiału wsadowego oraz reakcji powstałych w trakcie wytapiania i odlewania wlewków, dlatego też stop ten odlewany jest w próżni.

Tablica I. Skład chemiczny stopu Fe40Al5Cr0,2TiB Table I. Chemical composition of the Fe40Al5Cr0,2TiB alloy

\begin{tabular}{|c|c|c|c|c|c|}
\hline Fe40Al5Cr0,2TiB & Fe & Al & Cr & Ti & B \\
\hline $\begin{array}{c}\text { Zawartość pier- } \\
\text { wiastków [\% mas.] }\end{array}$ & 68,21 & 23,66 & 5,77 & 0,15 & 0,015 \\
\hline
\end{tabular}

W pracy analizowano możliwość wdrożenia metody napawania powierzchni stopem na osnowie fazy międzymetalicznej Fe40AI5Cr0,2TiB na materiale gatunku S235JR. Proces napawania przeprowadzono metodą TIG w osłonie gazów obojętnych. Parametry procesu zostały opisane w tablicy II.

Tablica II. Parametry procesu

Table II. Parameters of welding process

\begin{tabular}{|c|c|c|c|c|c|c|}
\hline TIG & $\begin{array}{c}\text { Grubość } \\
{[\mathrm{mm}]}\end{array}$ & $\begin{array}{c}\text { Osłona } \\
\text { gazowa }\end{array}$ & $\begin{array}{c}\text { Natę- } \\
\text { żenie } \\
\text { prądu } \\
{[A]}\end{array}$ & $\begin{array}{c}\text { Prze- } \\
\text { pływ } \\
{[\mathbf{I} / \mathrm{min}]}\end{array}$ & $\begin{array}{c}\text { Pozycja } \\
\text { spawa- } \\
\text { nia }\end{array}$ & $\begin{array}{c}\text { Pręd- } \\
\text { kość } \\
\text { spa- } \\
\text { wania } \\
\text { [mm/s] }\end{array}$ \\
\hline DC- & 5 & Argon I1 & 100 & 10 & PA & $1,0-2,5$ \\
\hline
\end{tabular}

Próby wykonane zostały w trzech wariantach: pojedynczy ścieg (SB), wielościegowy (MB), wielowarstwowy (ML). Rysunek 2 przedstawia schematycznie układ ściegów dla każdego wariantu.

Badania mikrostruktury warstwy napawanej ze stopu na osnowie fazy międzymetalicznej Fe40AI5Cr0,2TiB wykonano na zgładach polerowanych i trawionych chlorkiem żelaza. Obserwacje przeprowadzono z wykorzystaniem mikroskopu świetlnego OLYMPUS GX51.
Stop na osnowie fazy międzymetalicznej FeAl po odlaniu charakteryzuje się niejednorodną, gruboziarnistą mikrostrukturą oraz obecnością wad odlewniczych takich jak pustki, rzadzizny. Proces napawania stopu Fe40AI5Cr0,2TiB częściowo eliminuje wady odlewnicze (rys.3). Mikrostruktura stopu Fe40AI5Cr0,2TiB po napawaniu na podłoże ze stali S235JR obserwowana na przekroju poprzecznym w obrębie granicy wtopienia charakteryzuje się ziarnami o zróżnicowanej wielkości, w dużym stopniu wydłużonymi (kolumnowymi) podczas krystalizacji w kierunku największego gradientu temperatury.

a)

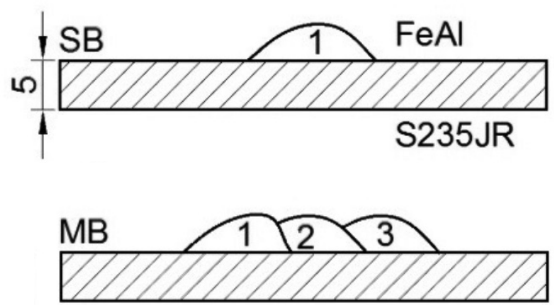

c)

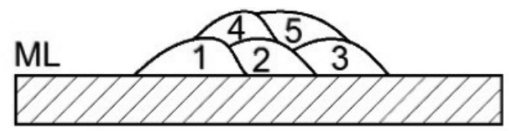

Rys. 2. Sposób nanoszenia powłoki na podłoże (liczba ściegów) Fig. 2. A method for applying a coating to a substrate (number of beads)
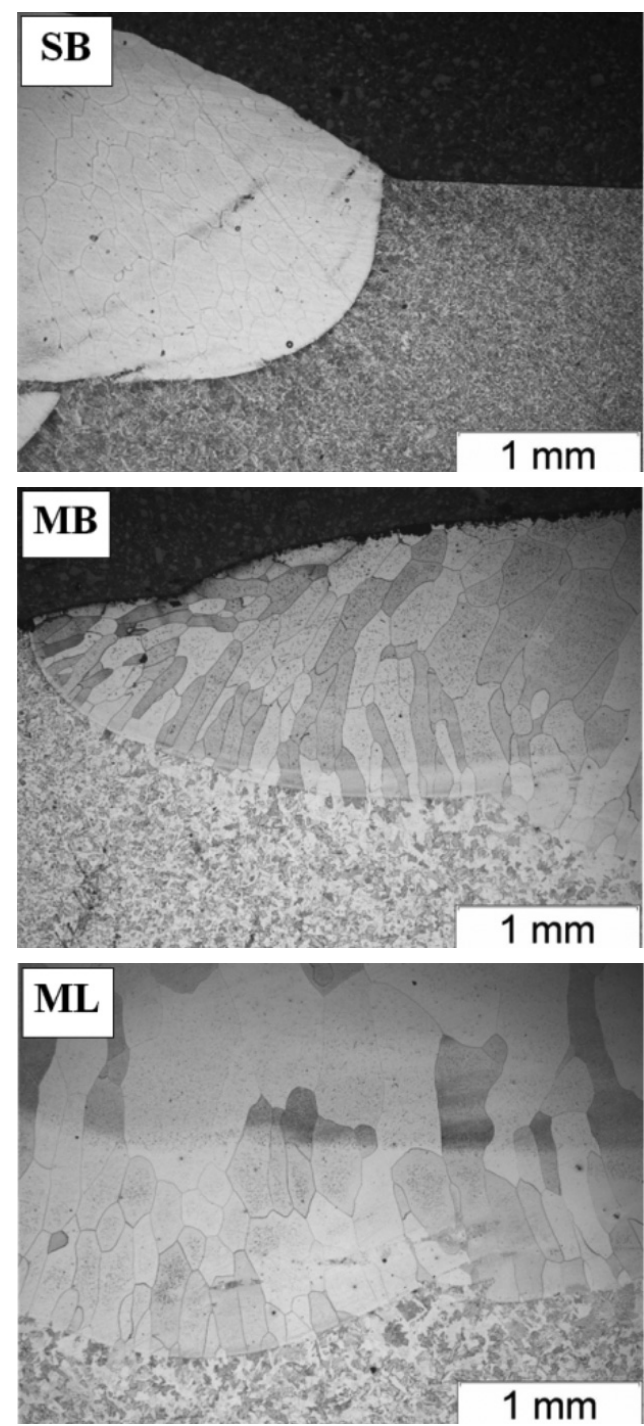

Rys. 3. Widok próbek z warstwą napawaną oraz wadami Fig. 3. View of welding samples with imperfection 
Pomiary twardości prowadzono na powierzchni przekrojów poprzecznych badanego materiału. Twardość mierzono metodą Vickersa zgodnie z PN-EN ISO 6507-1 przy obciążeniu 9,81 N (HV1) na twardościomierzu firmy ZWICK. Tablica III przedstawia wyniki pomiarów rozkładu twardości HV1 dla: $\mathrm{SB}, \mathrm{MB}, \mathrm{ML}$. Na rysunku 4 przedstawiono schematycznie miejsca przeprowadzenia pomiarów twardości.

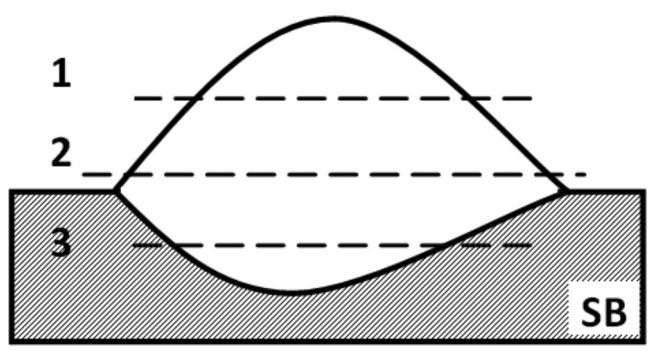

Rys. 4. Schemat prowadzenia pomiarów twardości w napoinie Fig. 4. A diagram of the measurement of hardness in the weld pad

Badania powierzchni wykonano przy pomocy elektronowego mikroskopu skaningowego (SEM) Hitachi S-4200 wraz z mikroanalizą rentgenowską składu chemicznego EDS. Rysunek 5 przedstawia mikrostrukturę warstw napawanych w układzie: jednościegowym (SB) (rys. 5a), wielościegowym (MB) (rys. 5b) i wielowarstwowym (ML) (fig.5c).

$\mathrm{Na}$ rysunku 6 przedstawiono wyniki mikroanalizy rentgenowskiej składu chemicznego powłok ze stopu Fe40Al$5 \mathrm{Cr0}, 2 \mathrm{TiB}$. Badania powierzchni za pomocą elektronowego mikroskopu skaningowego przeprowadzono na poprzecznych zgładach metalograficznych. Obserwacjom poddany zgłady trawione selektywnie z uwagi na znaczną różnicę w odporności korozyjnej materiału podłoża i napoiny (wynikającą z tego zróżnicowaną podatnością do ujawnienia mikrostruktury w procesie trawienia). Obserwacje wykonane za pomocą elektronowego mikroskopu skaningowego napoiny stopu międzymetalicznego FeAl wykazały gruboziarnistą strukturę warstwy napawanej oraz wyraźną linię rozdziału materiału rodzimego i materiału napoiny (FeAl). Badania składu chemicznego wykonane metodą mikroanalizy rentgenowskiej EDS wykazały zmniejszoną zawartość aluminium w napoinie oraz niezmieniony skład chemiczny stali w strefie wpływu ciepła. Zawartość aluminium w napoinie wynosi $12-20 \%$ at., co wskazuje na znaczny zgar aluminium w trakcie topienia podczas napawania. Zmniejszenie zawartości aluminium poniżej $37 \%$ at. skutkuje powstaniem stopu międzymetalicznego $\mathrm{Fe}_{3} \mathrm{Al}$. Wykonując napawanie stopem międzymetalicznym Fe40Al otrzymuje się napomnę $\mathrm{Fe}_{3} \mathrm{Al}$, której właściwości są odmienne od stopu użytego do napawania.
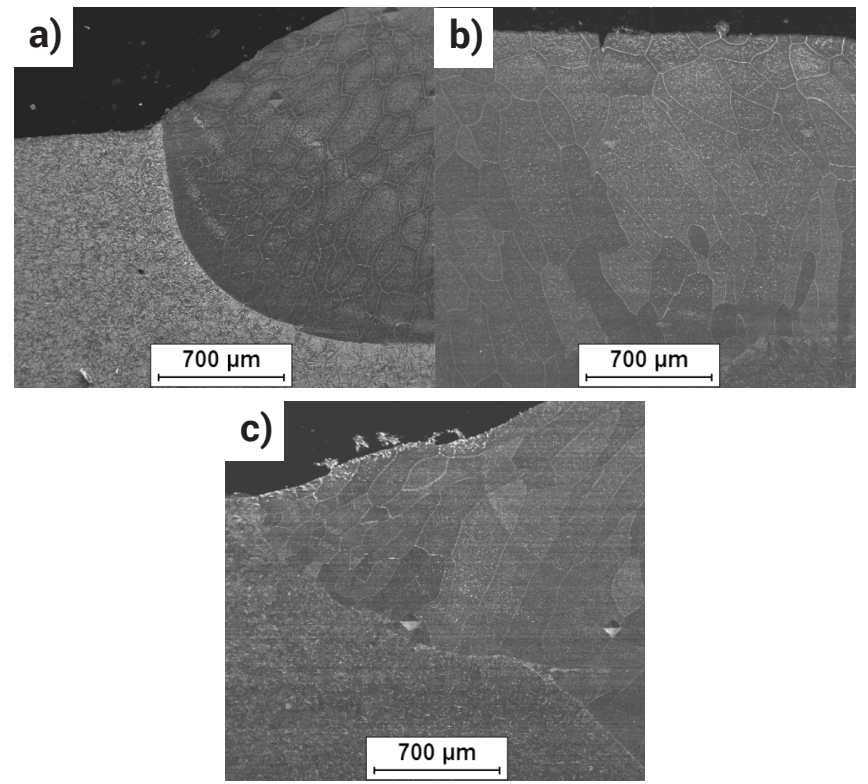

Rys. 5. Zdjęcia mikroskopowe linii wtopienia

Fig. 5. Microscopic view fusion line
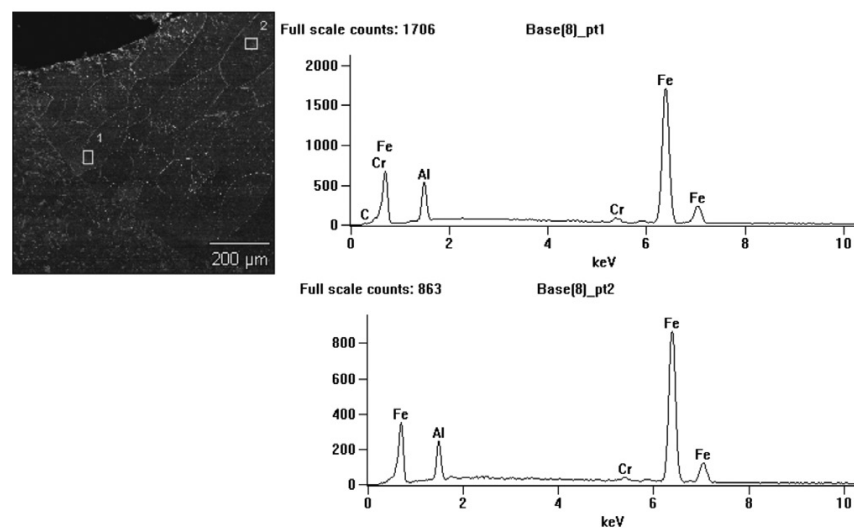

\begin{tabular}{|c|c|c|c|}
\hline Weight \% & Al & Cr & Fe \\
\hline Base(8)_pt1 & 7,2 & 1,7 & 91,2 \\
\hline Base(8)_pt2 & 6.2 & 1,0 & 92,7 \\
\hline Atom \% & Al & Cr & Fe \\
\hline Base(8)_pt1 & 13,7 & 1,7 & 84,6 \\
\hline Base(8)_pt2 & 12,1 & 1,1 & 86,9 \\
\hline
\end{tabular}

Rys. 6. Mikroanaliza rentgenowska składu chemicznego warstwy napawanej na próbce $\mathrm{ML}$

Fig. 6. X-ray microanalysis of the chemical composition of the weld layer on the sample MLe

Tablica III. Pomiary twardości

Table III. Hardness measurement

\begin{tabular}{|c|c|c|c|c|c|c|c|}
\hline \multicolumn{2}{|c|}{ Pomiar } & $\mathbf{1}$ & $\mathbf{2}$ & $\mathbf{3}$ & $\mathbf{4}$ & $\mathbf{5}$ & $\mathbf{6}$ \\
\hline \multirow{4}{*}{ Próbka SB } & Linia 1- góra & 218 & 212 & 216 & 205 & 243 & 240 \\
\cline { 2 - 9 } & Linia 2-środek & 218 & 238 & 250 & 233 & 231 & 237 \\
\cline { 2 - 9 } & Linia 3-dół & 206 & 198 & 226 & 243 & 217 & 236 \\
\hline \multirow{5}{*}{ Próbka MB } & Linia 1- góra & 230 & 286 & 240 & 334 & 275 & 331 \\
\cline { 2 - 9 } & Linia 2-środek & 289 & 257 & 313 & 295 & 292 & 278 \\
\cline { 2 - 9 } & Linia 3-dół & 265 & 297 & 238 & 226 & 260 & 240 \\
\hline \multirow{3}{*}{ Próbka ML } & Linia 1- góra & 302 & 345 & 292 & 297 & 299 & 301 \\
\cline { 2 - 9 } & Linia 2-środek & 297 & 342 & 323 & 312 & 278 & 316 \\
\cline { 2 - 9 } & Linia 3-dół & 248 & 224 & 236 & 241 & 231 & 249 \\
\hline
\end{tabular}




\section{Podsumowanie}

W ramach pracy wykazano możliwość wykonania napoiny stopu międzymetalicznego FeAl na stali konstrukcyjnej niestopowej metodą TIG przy zastosowaniu elektrody wolframowej oraz argonu jako gazu obojętnego. Proces napawania stopem międzymetalicznym Fe40Al5CrTiB powoduje uzyskanie mikrostruktury stopu o mniejszej ilości wad odlewniczych. Uzyskano ziarna kolumnowe w obszarze granicy wtopienia i ziarna zbliżone do równoosiowych w środkowej części napoiny otrzymując przy tym bardziej jednorodną mikrostrukturę w porównaniu do stopu po odlaniu. Wyniki badań wskazują, że prąd stały może być wykorzystywany do napawania tego rodzaju materiałów, jednak w napoinie mogą wystąpić niezgodności typu pęcherze. Tego rodzaju niezgodności znajdują się na granicy wtopienia lub w jej okolicy. Wykonanie powłoki wielowarstwowej znacznie redukuje ilość niezgodności, których obecność widoczna jest głównie w pierwszej warstwie napoiny. Kolejna warstwa napoiny była pozbawiona tego rodzaju defektów.

Uzyskano twardości od 198 HV1 do 345 HV1. W pierwszym ściegu (SB) maksymalna twardość wynosiła 250 HV1. Dla spawania wielościegowego (MB) uzyskano twardości od 226 do 331 HV1. W przypadku zastosowania spawania wielowarstwowego (ML) twardości mieściły się w przedziale od 224 do 249 HV1 w pierwszej warstwie, w strefie wymieszania między warstwami twardość mieściła się w zakresie 278-342 HV1, a w górnych warstwach 292 do 345 HV1.

Napoina wykonana ze stopu międzymetalicznego FeAl na stali konstrukcyjnej niestopowej charakteryzuje się gruboziarnistością oraz zmniejszoną zawartością aluminium w stosunku do zawartości tego pierwiastka w materiale użytym do napawania.

\section{Literatura}

[1] Bęczkowski R., Gucwa M.: Defects Appearing in the Surfacing Layers of Abrasion Resistant Archives of Foundry Engineering, 16 (4), s. 23-28, 2016.

[2] Białucki P., Derlukiewicz W.: Napawanie w regeneracji kokili do odlewania ciśnieniowego aluminium Przegląd Spawalnictwa, 10, s. 44-49, 2011.

[3] Bystrzycki J., Varin R.A.: Environmental sensitivity and mechanical behavior of boron-doped Fe-45at.\% Al intermetallic in the temperature range from 77 to $1000 \mathrm{~K}$ Materials Science and Engineering, A270, s. 151161,1999 .

[4] Cebulski J., Lalik S.: Badania strukturalne złączy spawanych ze stopu na osnowie fazy międzymetalicznej Fe-Al Przegląd Spawalnictwa,1, s. 2426, 2010.

[5] Cebulski J., Fornalczyk A., Pasek D: The kinetic of corrosion of the FeAl intermetallic phase-based alloys Journal of Achievements in Materials and Manufacturing Engineering, 70 (2), s.53-59, 2016.

[6] Dobrzański L.A.: Podstawy nauki o materiałach i metaloznawstwo Gliwice, 2002.

[7] Dymek S.: Charakterystyka wysokotemperaturowych związków międzymetalicznych" Hutnik-Wiadomości Hutnicze, 6, 208-223,1998.

[8] Kupka M.: Struktura i właściwości stopów FeAl otrzymanych w procesach metalurgicznych Wydawnictwo Uniwersytetu Śląskiego, Katowice, 2005.

[9] Tasak E., Ziewiec A., Parzych S.: The influence of the heat treatment on the properties of welded joints made with use of submerged arc welding and the GTAW method of the 7CrMoVTiB10-10 steel Powerwelding Conference, s. 179-188, 2011.

[10] Gontarz G., Golański D., Chmielewski T. Properties Fe-Al type intermetallic layers produced by AC TIG method Advances in Materials Science, 13, 3 (37), s. 5-16, 2013.

[11] Chmielewski T., Golański D.: The new method of in-situ fabrication of protective coatings based on FeAl intermetallic compounds" Proceedings of the Institution of Mechanical Engineers Journal of Engineering Manufacture, Part B, 225 (4), s.611-616, 2011. 